\title{
Territorio habitado y territorio como derecho: reflexiones desde el caminar Kichwa Lamista*
}

Inhabited territory and territory as a right: reflections from the Kichwa Lamista walking

\begin{abstract}
RESUMEN
Este artículo plantea una aproximación al territorio Kichwa Lamista, en la alta Amazonía peruana, desde el seguimiento de los caminos que alimentan sus relaciones. Dentro de ellos, se consideran también sus caminos por la defensa de este territorio como un derecho y cómo estos se entrelazan con los de otras personas que acompañan este recorrido. Como parte de ello, se contemplan las fuerzas que impulsan sus movimientos y las que los restringen, así como las formas en que el caminar constituye a las personas, los vínculos entre ellas y con otros seres y la regeneración del conocimiento.
\end{abstract}

Palabras clave: Caminar, Cuerpo, Territorio, Amazonía, Kichwa.

\section{Abstract}

This article proposes an approach to the Kichwa Lamista territory in the upper Peruvian Amazon from the follow-up of the trails that nourish their relationships. Among them, the pathways for the defense of this territory are also considered as a right and how they intertwine with those of other people who accompany this journey. As part of this, the forces that drive their movements and those that restrict them are considered as well as the ways in which walking constitutes people,

\author{
Anahí Chaparro \\ Magíster en Antropología por la \\ Universidad Federal Fluminense. \\ Doctoranda en Antropología \\ en el Museo Nacional - \\ Universidad Federal de Río de \\ Janeiro, Río de Janeiro, Brasil. \\ $\checkmark$ anahichaparro@ufrj.br \\ (D) ORCID: 0000-0001-7321-4307 \\ $\checkmark$ Google Scholar \\ *Este artículo presenta las reflexiones \\ elaboradas en mi investigación de \\ maestría, que fue posible gracias \\ a la beca Nota 10 de la Fundação \\ Carlos Chagas Filho de Amparo \\ à Pesquisa do Estado do Rio de \\ Janeiro. Agradezco a las profesoras \\ que me acompañaron en este \\ proceso. A mi asesora, Eliane \\ O’Dywer, mi co-asesora, Deborah \\ Bronz, y a Luisa Elvira Belaúnde. \\ Asimismo, a los que participaron \\ como jurados en mi sustentación, \\ Oiara Bonilla y Edmundo Pereira, y \\ a los evaluadores ciegos del artículo \\ que contribuyeron con valiosos \\ comentarios. Finalmente, agradezco \\ a mis compañeros de trabajo de las \\ distintas instituciones, organizaciones \\ indígenas y comunidades Kichwa con \\ los que compartimos los caminos \\ aquí descritos. En especial, a todas \\ las personas de la comunidad de \\ Alto Pucalpillo, que me acogieron \\ con gran generosidad. Los \\ posibles errores $u$ omisiones son \\ de mi entera responsabilidad.
}


the links between them and with other beings and the regeneration of knowledge.

Keywords: Walking, Body, Territory, Amazon region, Kichwa.

\section{Introducción}

Ste artículo plantea una aproximación al territorio Kichwa
Lamista en la alta Amazonía peruana, desde el seguimiento de
los caminos que alimentan sus relaciones. Dentro de ellos, se consideran también sus caminos por la defensa de este territorio como un derecho y cómo estos se entrelazan con los de otras personas que acompañan este recorrido.

Como se desarrolla a lo largo de este artículo, el territorio habitado por los Kichwa Lamista no está constituido por un espacio continuo, como lo presupone la normativa sobre comunidades nativas, categoría con la que se reconoce la personería jurídica y el derecho a la tierra de las familias indígenas de la Amazonía en la legislación peruana. Tampoco abarca zonas de uso distribuidas en círculos concéntricos -el más cercano compuesto por la casa colectiva y huertos, un segundo de cultivo, caza y recolección cotidiano y un tercero para las expediciones de largas distancias- como se pensó el uso del espacio de los pueblos indígenas amazónicos desde la antropología, según señalan Albert y Le Tourneau (2007) a partir de su experiencia con los Yanomami. En vez de eso, puede ser descrito, siguiendo a estos autores, como un "espacio reticular" conformado por diferentes caminos familiares que articulan lugares interconectados también con otras redes de caminos. En este sentido, recuerdan la noción de Ingold $(2002,2009,2011)$ de los lugares como mallas (meshworks) de movimientos.

La población que se identifica hoy en día como Kichwa Lamista o de Lamas -antes, también, se autodenominaban Lamas Runa (Gente de Lamas) o Jakwash- está conformada por familias que proceden de esta ciudad, específicamente del Wayku, como se denomina a la parte baja de la misma. Algunas mantienen una casa ahí, a donde regresan esporádicamente los fines de semana y, principalmente, para la fiesta de Santa Rosa. Actualmente, las familias Lamista practican una forma de residencia multi-localizada caracterizada por un desplazamiento constante entre sus pueblos, los de sus parientes, Lamas, sus chacras y sus lugares de caza, pesca y recolección. 
En esta circulación, el movimiento de volver tiene una importancia particular para la reproducción de las relaciones y la vida humana, como también nota Virtanen (2016) en su trabajo con los Manchineri de la Amazonía brasilera. En el caso de los Kichwa Lamista, volver define su relación con Lamas. A este lugar, como dicen cuando se expresan en castellano, siempre vuelven, nunca van. En kichwa, volver puede traducirse de dos formas dependiendo de su direccionalidad: como kutiy (volver de acá para allá) y kutimuy (volver de allá para acá) ${ }^{1}$. Frente a ello, este artículo plantea una reflexión sobre cómo la relación entre las personas y de estas con los lugares que habitan está modelada por fuerzas que restringen sus movimientos y fuerzas que los impulsan en diferentes direcciones, incluidas los que los traen de vuelta.

Lamas fue el mayor centro colonial donde se concentraron distintos grupos indígenas del río Mayo y de la parte medio y baja del río Huallaga. Los Kichwa de Lamas, dependiendo del contexto, pueden diferenciarse de otros Kichwa de la región San Martín, vinculados a otros antiguos centros coloniales, como los de Sisa o los del Huallaga. Sus caminos abarcan diferentes microclimas, tipos de tierra y recorren montañas accidentadas entre los 400 y 2500 metros sobre el nivel del mar.

Los Lamista continúan movilizándose pese a los intentos por sedentarizarlos en espacios reducidos. En las últimas décadas, se han visto desplazados de las partes bajas de las cuencas debido al aumento exponencial de la inmigración desde los Andes desde la construcción de la carretera Fernando Belaúnde Terry (también conocida como carretera Marginal de la Selva), que en muchos casos produjo enfrentamientos violentos. La apertura de estas vías de comunicación facilitó la expansión del cultivo de coca y el incremento del narcotráfico, vinculado a grupos subversivos, durante el periodo de conflicto armado interno que atravesó el Perú en las décadas de los ochenta y noventa².

La confrontación entre los grupos subversivos y los militares limitó también, durante ese periodo, la movilidad de los Kichwa Lamista, según testimonios de distintas comunidades, en tanto parte de los caminos que

\footnotetext{
El sufijo "mu" puede encontrarse en otros verbos, como challamuy (llegar de allá para acá) que deriva de challay (llegar de aquí para allá) o apamuy (traer) que deriva de apay (llevar).

La forma de referirse a este período fue motivo de un debate intenso durante la elaboración del Informe Final elaborado por la Comisión de la Verdad y Reconciliación, a inicios de la década del 2000, debido a las diferentes maneras de entender lo que ocurrió en el Perú en esos años. No tengo espacio para traer aquí esa discusión, pero retomo la nomenclatura que finalmente fue adoptada en el informe, tanto para la noción de "conflicto armado interno" como para la de "grupos subversivos". En San Martín, el de mayor presencia fue el Movimiento Revolucionario Tupac Amaru (MRTA). En esta región, las implicancias de este periodo de violencia duraron más que en otras partes del país, entrados los años noventa.
} 
recorrían a pie por las montañas de la región se convirtieron en rutas para el transporte de coca. El principal temor de las personas se debía al riesgo de ser encontradas por los militares, que solían acusar a la población de rural de terrorista. El Wayra Purina (Camino del Viento) -lugar donde se encuentran las almas de los yachak (literalmente, "el que sabe", como se llama a los médicos o chamanes), al igual que en el cerro Waman Wasi (Casa del Gavilán)-, punto de paso en el camino de la sal que se delinea posteriormente, era cocido por ser donde los militares tiraban los cuerpos de las personas asesinadas durante esa época.

A fin de frenar las altas tasas de deforestación generadas por el contexto descrito, en los últimos quince años, se implementaron en la región una serie de políticas de gestión ambiental que, entre otras estrategias, incluyó la creación de áreas de conservación que han criminalizado las actividades de los pueblos indígenas (Chaparro y Valderrama, 2017 y Chaparro, 2018). La que ha tenido mayor impacto en la vida de los Kichwa Lamista es el área de conservación regional Cordillera Escalera, creada en el 2005 sin cumplir con la consulta previa, libre e informada. En el 2010, ocho personas de la comunidad de Alto Pucalpillo fueron enjuiciados por realizar labores agrícolas dentro esta área. A pesar de no ser sentenciados como culpables, al dictaminar que fue un "error culturalmente condicionado", fueron obligados a abandonar sus cultivos. Posteriormente, personas de otras comunidades Kichwa, como Ankash Yaku de Achinamisa y El Piñal, han sido denunciadas por los mismos motivos.

Esta reflexión parte de mi experiencia anterior con los Kichwa en San Martín. Desde agosto de 2013 hasta febrero de 2016, y desde julio de 2018 a diciembre de 2019, trabajé en una organización no gubernamental en un proyecto con el objetivo de acompañar a las organizaciones indígenas en la defensa de sus derechos territoriales. Asimismo, realicé mi investigación de maestría junto a las personas de la comunidad de Alto Pucalpillo sobre su sentido de caminar (puriy) y el vínculo con sus relaciones de crianza (wiway) frente a las fronteras que interrumpen su flujo (Chaparro, 2018). El trabajo de campo se realizó entre junio y septiembre de 2017. Entre sus caminos, me detuve más tiempo en los que recorren el área de conservación Cordillera Escalera.

Durante el periodo de mi investigación de maestría, algunas comunidades Kichwa habían decidido exigir judicialmente el respeto de sus derechos territoriales, específicamente del cumplimiento del Convenio n. ${ }^{\circ} 169$ de la Organización Internacional del Trabajo. Estas ya habían intentado alcanzar este objetivo por la vía burocrática, con protestas en las ciudades y participando en mesas de diálogo. Esto había logrado algunos avances. 
Entre ellos, la adjudicación de los títulos habilitantes a la primera comunidad dentro de Cordillera Escalera, Nuevo Lamas de Shapaja, cuyo núcleo poblacional se encuentra dentro de esta área. Sin embargo, las comunidades cuyos principales asentamientos están en los alrededores de Lamas seguían siendo excluidas. En ese contexto, como hablamos con los líderes Kichwa y los abogados, mi investigación podía dar elementos para pensar la dinámica territorial de este pueblo. Por lo que uno de los documentos producto de esta fue un peritaje antropológico.

Como parte de esta reflexión, retomo la propuesta de Gupta y Ferguson (1997) y su lectura de Donna Haraway sobre el quehacer antropológico como parte de un proceso de construcción de redes entre diferentes localizaciones. Así, resalto la convivencia del conocimiento antropológico con otras formas de conocimiento y su colaboración para la intervención estratégica que, en este caso, se traduce en el caminar juntos.

Esta expresión retoma la importancia dada por los Kichwa Lamista al caminar para la constitución de las personas, para el mantenimiento de las relaciones entre ellas y con otros seres, para la regeneración de la memoria y el conocimiento, y para la construcción de la noción política de territorio y la movilización de las comunidades en su defensa como un derecho. El complemento "juntos" hace referencia a los valores morales que canalizan los modos de socialidad Lamista. Esta incorpora, en primer lugar, a los parientes cercanos, pero se extiende a las demás personas con las que establecen relaciones variadas de intercambio de flujos. Así, este trabajo presenta los movimientos de las familias Kichwa Lamista y de Alto Pucalpillo en particular, en los que caminar (puriy) y criar (wiway) forman parte de una continuidad, siempre y cuando se pueda volver (kutiy o kutimuy) para seguir compartiendo.

\section{Saber caminar}

Los registros coloniales cuentan el rol que cumplían los Lamista como cargadores a través de las rutas de comercio que atravesaban las montañas desde la ciudad de Moyobamba hasta la de Yurimaguas, donde se encontraba el puerto de donde navegaban los barcos en dirección al Atlántico (Scazzocchio, 1979). Las personas de Alto Pucalpillo, hoy en día, recuerdan las historias de sus abuelos sobre los caminos que estos recorrían a pie, evocando los abusos de las autoridades no indígenas o de sus patrones que los obligaban a realizar trabajos forzados -que continuaron hasta entrado el siglo XX bajo el "sistema de enganche" o servidumbre por endeudamiento-, pero también orgullosos de la fuerza y destreza que 
esta habilidad requería. Esta misma se demostraba en las antiguas pruebas que hacían pasar los suegros a sus yernos para poder convivir con sus hijas. Para ello, debían llevar a pie una carga de 60 kilos de la ciudad de Lamas hasta la de Moyobamba, a unos 80 kilómetros, y regresar.

Varios trabajos sobre los pueblos indígenas amazónicos enfatizan la inseparabilidad del cuerpo y el conocimiento, como la reflexión sobre los "cuerpos que saben" de Kensinger (1995) y McCallum (1996) a partir de su investigación con los Huni-Kui. En este sentido, caminar, además de una forma de movilizarse, es un saber del cuerpo. Por eso, en Alto Pucalpillo, mencionan en repetidas oportunidades que hay que saber caminar para ir al monte: saber pisar en el terreno accidentado, controlar el peso del cuerpo y la carga usando una pretina colocada en la cabeza, no hacer ruido para no espantar a los animales ni enfadar a su dueño, imitar los sonidos del bosque, preparar el cuerpo con ciertas plantas y cortezas para tener fuerza y que los animales se acerquen, entre otras habilidades (Chaparro, 2018).

Las reflexiones de Kensinger (1995) y McCallum (1996) se insertan en la discusión medular de la etnología de las tierras bajas sudamericanas sobre la construcción de la noción de persona -vinculada a la reproducción del parentesco- a partir de modos de consubstancialización, en los que la corporalidad ocupa un lugar central. Estas investigaciones -desarrolladas por varios autores como Da Matta (1976), Overing (1977), Seeger, Da Matta y Viveiros de Castro (1979), Viveiros de Castro (1979), Vilaça (1992), Gow (1991), Belaúnde (2001), Lima (2002), entre otrosretoman las distintas formas de intervención de los canales de contacto entre el cuerpo y el mundo mediante la manipulación de sustancias (de sangre, semen, alimentos, vegetales y, como se ve más adelante, condimentos como la sal) para introducir o sacarlas del cuerpo y colaborar, así, con su crecimiento y fortalecimiento (Viveiros de Castro, 1979, pp. 45-46). Estos procedimientos involucran relaciones con la alteridad al incluir la incorporación o familiarización de la agencia de otros seres (personas, animales, plantas y otros).

En su reflexión sobre los modos de sociabilidad indígena amazónica, enfocada en la economía simbólica de la alteridad, Viveiros de Castro (1998) señala el cuerpo como el lugar de la perspectiva, donde se localiza la particularidad de cada ser (en tanto el alma sería lo compartido por los distintos seres que se conciben como sujetos). Así, el autor recalca cómo, en este modelo, cada cuerpo se define por "lo que come, cómo se mueve, cómo se comunica, dónde vive, si es gregario o solitario" (1998, p. 478, traducción propia). Además, en tanto los cuerpos son mutables, es en ellos que se marcan las similitudes y diferencias que constituyen las relaciones. 
Retomando estos aportes, en su trabajo con los Runa del Pastaza ecuatoriano, Mezzenzana $(2015,2018)$ profundiza en la importancia del movimiento al momento de marcar la alteridad y en el proceso de transformarse en semejantes, frente a lo que la autora también recuerda el peligro intrínseco que conlleva volverse demasiado similar a otro. Así como Mezzenzana nota que los Runa del Pastaza son observadores perceptivos de sus propios movimientos y de los de los otros - por ejemplo, en las bromas sobre cómo ella parecía un tapir en el lodo cuando cruzaba un arroyo-, Calderón (2003) señala cómo los Kichwa Lamista diferencian sus movimientos corporales de los de quienes identifican como mestizos, que consideran exagerados, desequilibrados y bruscos $^{3}$. En mi propia experiencia, el periodo que viví en Alto Pucalpillo también estuvo atravesado por las observaciones sobre las diferencias corporales entre mis anfitriones y yo, así como por intentos de moldear mi cuerpo, como al querer acostumbrarme a comer alimentos que antes no había probado o vestirme con su ropa para las fiestas (ver Chaparro, 2018). Mi forma de caminar era uno de los movimientos observados. En la comunidad, algunas de las niñas me imitaban y bromeaban porque decían que movía mucho las caderas. Igualmente, en el monte, mis compañeros de excursión bromeaban diciendo que parecía una vaca cuando respiraba muy fuerte por la agitación de las subidas.

Mezzenzana $(2015,2018)$ también parte de la relación entre la Abuela de la Arcilla - poseedora del saber para la confección de cerámicas- y las mujeres Runa para apuntar al papel de la imitación del movimiento en el modelamiento de los cuerpos, la constitución de semejanzas y la transmisión de conocimiento entre humanos y no humanos. La autora dialoga con autores como Ingold y Lee (2008) que enfatizan cómo caminar es una forma de conocer, no en tanto medio, sino en tanto el movimiento es un tipo de conocimiento en sí mismo.

En el caso de los Kichwa Lamista, el saber caminar constituye una relación distinta con el monte que la que se prioriza cada vez más en los proyectos de conversación mediante la vigilancia satelital de los bosques. Como afirmó don Purificación Cachique, un día que estábamos reunidos en Alto Pucalpillo planificando una salida para visitar el lugar donde había sido denunciados don Ramón y sus parientes utilizando las imágenes de Google Earth: "Carachupa [refiriéndose a una persona por su apodo] camina por tierra, no como los gringos por satelital. Los wawkis [hermanos]

Según Calderón (2003), la diferenciación es mutua. Él describe los movimientos de los Lamista como menos expresivos que los de los llamados mestizos, lo que estos últimos relacionan con una actitud de extrema humildad, falta de virilidad o poca autoestima (pp. 82-83) 
caminan por las purinas [caminos]" (P. Cachique, comunicación personal, julio de 2017). Lo importante era ir allí, caminar, hacer conocer a los más jóvenes los sonidos y movimientos de los seres del monte y llegar a la punta de los cerros para ver los recorridos de los ríos.

De esta manera, los Lamista aprenden a caminar desde pequeños acompañando a los parientes a la chacra y al monte, así como mediante las dietas que transmiten el conocimiento de las plantas y otros secretos -concepto que denota un saber con resultados efectivos ${ }^{4}$ que potencian las semejanzas con los animales. Después del parto, la placenta puede ser enterrada en varios lugares vinculados a la familia: en la chacra, el cementerio, una tierra pantanosa o húmeda cerca de la casa, la casa del armadillo o de las hormigas. En este último caso, se hace para que el niño sea caminante y fuerte como una hormiga (Tapullima, 2012). Mientras van creciendo, se continúa preparando el cuerpo de los niños a fin de incorporar los atributos de los seres de su entorno para moldear sus habilidades y temperamento. Así, en resonancia con las reflexiones sobre los modos de consubstancialización que desarrolla la bibliografía citada anteriormente, según don Jaime Amasifuen Cachique:

Para que el niño sea fuerte se le soba con la manteca del zorro y del oso en las piernas y manos, se lo hace tomar una gota de manteca, para que no pase nada cuando cae al caminar, es decir, posea las habilidades del animal. [...] En todos mis hijos cuando han nacido, siempre tengo la ishpa (licor) en la casa, el que me visita siempre retorna calentando su cuerpo, es decir probando la ishpa, eso es de costumbre en nosotros, eso preparamos con alegría porque vamos a tener un miembro más en la familia, al mismo tiempo esta costumbre hacemos para que pueda caminar rápido y crezca rápido el muchacho y nos pueda acompañar al monte. (Citado en Tapullima, 2012, p. 311) $)^{5}$

Por otro lado, también existen restricciones y cuidados que los padres deben mantener para no afectar las habilidades de los hijos. Por ejemplo, de acuerdo a lo que me indicó Rita Cachique Sangama las

\footnotetext{
Que se pueden vincular a la noción de paju, de los Runa del Pastaza ecuatoriano, que, según Mezzenzana, se refiere a la potencia que tienen los movimientos de unos para afectar los movimientos de otros, además de a un estado de enfermedad producido por "movimientos impropios" (2018, p. 5).

Parte de los testimonios aquí citados han sido recogidos por personas vinculadas a las organizaciones no gubernamentales Asociación Rural Amazónica Andina Choba Choba y Waman Wasi Centro para la Biodiversidad y Espiritualidad Andino Amazónica —ambas asociadas al Proyecto Andino de Tecnologías Campesinas (PRATEC) - en publicaciones sobre los saberes para la crianza de la chacra y el monte, a partir de un trabajo de más de 20 años con los Kichwa Lamista. En todos los casos mantenemos los nombres originales para respetar los aportes de los conocimientos que han trasmitido.
} 
mujeres no pueden confeccionar vasijas de cerámica cuando tienen hijos pequeños que todavía no caminan debido a que estos pueden demorarse más en aprender. Cuando ya andan, antes de empezar a embarrar nuevamente, deben darle golpecitos con arcilla en las plantas de las manos y los pies.

Los adultos llevan a los niños a la chacra para que se acostumbren a no ser perezosos y a cargar todo lo que crían. Según afirma Carolina Guerra Cachique (citada en Tapullima, 2012, p. 305), esto les enseña a pensar en la familia, en lo que hace falta en la cocina, para que sean después buenos padres y madres. De esta forma, el caminar y cargar moldean no solo el cuerpo, sino también la personalidad y las relaciones. Asimismo, se valora a los niños curiosos que, según sus gustos, buscan aprender con los mayores y desarrollar habilidades. A estos, como afirma Panduro (2012), se les dice que caminan con el pensamiento. Ello implica también cultivar los afectos. Como señala Gow (1989) en su trabajo sobre los Piro de la Amazonía peruana, es la memoria incorporada de los cuidados recibidos lo que permite alimentar las relaciones de parentesco. Pero estas relaciones no se conciben como algo dado. Como afirma don Pedro Sangama Sangama, los nietos "se alejan nomás si no se les cría con gusto" (citado en Tapullima, 2012, p. 305).

Por otro lado, así como el caminar está vinculado al cuidado de la familia y al desarrollo de los afectos, también permite la relación con la alteridad para la obtención de bienes, conocimientos ajenos y generación de alianzas. Como menciona Virtanen (2016) en su reflexión sobre las estadías de los Manchineri en las ciudades, la (re)producción de los conocimientos, los lugares y las relaciones forma parte de un movimiento continuo en el espacio que teje con otros una red en constante transformación ${ }^{6}$. Scazzocchio (1978) cuenta que los viajes largos de comercio o trabajo -incluido durante el llamado "boom del caucho", en el que los Lamista sirvieron de mano de obra en las zonas de extraccióneran comunes y formaban parte de la socialización de los hombres jóvenes Kichwa de Lamas. El primer viaje solo marcaba la independencia del padre. Después, podían llevar a sus hijos y quedarse lejos de casa varios meses o un año. Antes de partir, abrían una chacra para su esposa y dependientes, y buscaban a alguien que ayudara a cultivarla a cambio de una parte de la cosecha o de algún objeto traído del viaje. La autora menciona que, cuando realizó su trabajo de campo en la década del setenta, el servicio

Ver también las reflexiones de Bonilla (2006) sobre los periodos de convivencia de los Paumari con sus patrones, durante los cuales los primeros buscan aprender "las formas de los blancos", además de establecer relaciones de confianza para obtener un acceso privilegiado a mercancías. 
militar tenía un significado similar para los Lamista. Igualmente, hace un paralelo con los viajes de iniciación de los chamanes o yachak (sabio), que implicaban buscar a un maestro de fuera en un circuito de intercambio de conocimientos por bienes que iba de sur a norte: los Cholón aprendían con los Lamista y estos últimos viajaban donde los Jebero, Murato o Ashapra. Aunque la autora aclara que estos viajes eran más largos en tanto debían realizar dietas - periodos de resguardo y tratamientos medicinales- que duraban dos o tres años. Actualmente, algunos hombres adultos cuentan que, antes de ir al servicio militar, también prepararon su cuerpo con una dieta de varios meses. A diferencia de sus padres, los jóvenes de hoy ya no están obligados a prestar este servicio. No obstante, sigue siendo valorado como un momento para aprender a vivir en las montañas y a manejar armas que luego usan para cazar.

Las dietas son tratamientos medicinales que implican el uso de preparados con plantas, raíces y/o cortezas, y una serie de restricciones alimentarias y sexuales. Son formas de preparar el cuerpo para que esté sano y fuerte mediante la ingestión y baños que varían considerablemente en objetivos, niveles de aislamiento, sustancias transmitidas y restringidas a través de los diferentes sentidos, como el paladar, el olfato, la visión y el tacto. Mediante las dietas, el cuerpo adopta las características de los vegetales que se incorporan, como su olor. Así, los montaraces -como se llama a los cazadores que saben caminar en el bosque- dietan para volverse parte del monte. Existen dietas para tener mejor puntería, fuerza para caminar y/o flexibilidad.

Don Nazario Sangama Salas describe los beneficios de las diferentes purgas y su relación con la fortaleza corporal de la siguiente manera:

El sanango es muy bueno para la caza, dirige la puntería. El ajosacha amansa al venado. El clavo huasca también es una purga buena, si le toma unas seis semanas. Te hace buen carguero. (...) Estas purgas son para la fuerza, para no tener sueño, para todo te cura la purga. La renaquilla todos toman. Mi papá sabe preparar el tamborhuasca, a nosotros nos ha hecho dietar desde muy muchachos. Por eso conozco. Yo tengo 30 años y así como me ven, cuerpo chiquito, traigo cargando de 60 a 70 kilos de mitayo [carne de los animales del monte]. (Citado en Panduro y Rengifo, 2001, p. 24)

Por su parte, al señalar los efectos de estos tratamientos medicinales, don Purificación Cachique Tuanama, abuelo de Alto Pucalpillo, enfatiza los diferentes vínculos que puede establecer el montaraz con los seres del monte: 
El monte tiene su sonido, el viento tiene su música: el muyuhuayra (de muyuy, círculo, y huayra, viento) es su danza. ¿No pues suena cuando corre el viento entre los árboles? Esa es su música. Cuando tu cuerpo es curado, los animales son como tus hermanos, hasta tu tambo [vivienda pequeña construida en la chacra o en el monte] se van. En un árbol están cantando, se acercan. Esos animales están cantando, de allí se agarra su música, pues uno mismo se está monte [mi énfasis]. Cuando se toma purga todo animal es tu amigo, hasta el chullachaqui es tu amigo. Todas las danzas que entonamos en didín [tambor pequeño] y pífano [flauta de caña] es lo que escuchamos en el monte. Del monte vienes a tu casa y allí ya entonas, sino olvidas. Debes tener buena cabeza para acordar lo que oyes en el monte. (Citado en Panduro y Rengifo, 2001, p. 126)

Este muyuy recuerda también las danzas de los humanos, como la kajada, en la que principalmente los abuelos bailan lentamente, las mujeres en una rueda interna, a veces girando sobre ellas mismas, y los hombres en una rueda externa, tocando silbatos para marcar el ritmo y el momento de cambiar de dirección; o la pandilla, bailada principalmente por los jóvenes, hombres y mujeres tomados de los brazos, corriendo velozmente en círculos. Panduro relaciona los movimientos de kutiy (volver) y muyuy (dar vueltas, circular o intercambiar) con el ciclo de la vida que, en el caso de los seres humanos, la chacra, el monte, los animales y otros seres, maduran, mueren y se regeneran nuevamente (2012, p. 295).

Así, las danzas recuerdan cómo cada momento de ciclo vital tiene su propio ritmo, al igual que el andar de las personas. A los jóvenes les gusta caminar. Cuando los solteros salen de fiesta a buscar a las muchachas se suele decir que salen a chapanear, verbo con raíz kichwa castellanizado -forma común en el uso local de esta lengua- utilizado para referirse a las excursiones de caza y vinculado al sentido de la vista, como se explica posteriormente. Al comentarme esta actitud, doña Rosario Sangama Cachique comparaba cómo a muchos jóvenes andariegos les gusta vivir caminando y no crían nada, mientras que otros comienzan a criar desde temprano. Por otro lado, y aunque existen diferentes motivos para cambiar sus lugares de residencia durante la vida adulta, llega un momento en que el ritmo de movilidad disminuye. "Yo estoy sembrada aquí ya, aquí voy a morir", fueron las palabras que utilizó doña Jesús Guerra Cachique para expresarme esta forma de arraigo. Cuando las personas son mayores, las relaciones de cuidado también se invierten y, según las palabras que usan los Kichwa Lamista, son los hijos que crían a sus padres. 


\section{Los caminos Kichwa Lamista desde Alto Pucalpillo}

Desde la llegada de los primeros europeos, se produjeron varios intentos para confinar espacialmente a los grupos indígenas que hoy en día se identifican como Lamista. No obstante, la memoria de los caminos se continúa transmitiendo y actualizando. Este es un conocimiento vivo compartido con los antiguos que están presentes en las huellas que han dejado al andar, como expresan las citas posteriores.

Scazzocchio (1979) narra cómo, desde finales del siglo XVIII, con la terminación de las misiones, los indígenas de Lamas obtuvieron mayor independencia para movilizarse y ocupar periódicamente sus territorios de caza a uno o dos días de camino, formando nuevos pueblos. A este movimiento, que se intensificó en el siglo siguiente, esta autora lo llama ciclo llakta (pueblo).

En las últimas décadas, en los alrededores de Lamas, este ha consistido en la agrupación de las familias que tenían chacras cercanas. En otros casos, algunas familias han decidido desplazarse juntas a sus zonas de caza más alejadas o a lugares que han conocido en sus trabajos, como en los recorridos de los músicos. Los motivos para establecer nuevos lugares de residencia han sido varios. Hoy en día, están vinculados al interés por buscar sitios con abundancia de animales, donde haya escuelas para la educación de sus hijos -lo que puede implicar que solo la madre, los hijos más pequeños y los estudiantes se muden-, para la apertura de nuevas chacras, por la ocurrencia de plagas o por los conflictos entre familias o con invasores.

Por esta movilidad, los Kichwa Lamista se comparan a sí mismos a los mallki de plátano, su alimento diario. Los mallki son los retoños que nacen del rizoma de la planta madre que, para poder crecer sin apegarse, se siembran en lugares más alejados. Scazzocchio (1979) afirma que el término mallki puede utilizarse como sinónimos de ayllu, grupo de parentesco que, dependiendo del contexto, identifica a familias constituidas por relaciones de descendencia y afinidad, a los que comparten el mismo apellido, asociado a un barrio del Wayku, o a los Kichwa Lamista como un todo. Este movimiento de los mallki dialoga con el sentido de rizoma que esbozan Deleuze y Guattari (2012) en tanto líneas que se expanden en todas las direcciones, atravesados por otras líneas, sin constituir formas cerradas ni establecer relaciones definitivas. Para que los vínculos se mantengan, se debe continuar alimentando los afectos a través de los cuidados. Si no, estos pueden debilitarse u olvidarse. 


\section{Celebrar la vida}

La principal ocasión en la que se reúnen las familias Lamista de distintas comunidades en Lamas es la fiesta de Santa Rosa, que se celebra entre el 21 y el 31 de agosto y coincide con la campaña grande de siembra de maíz. Esta fiesta - también llamada Inti Maray (inti es sol y maray, un verbo que se puede traducir como golpear o derribar)- así como el Corpus Christi o Corpus Inti, entre otras, también se relacionan al camino del sol. Como menciona Juan Sangama de la comunidad de Pucallpa:

Hay una nube blanca también que atraviesa el espacio, que aparece lleno de estrellas, eso aparece ya desde abril y mayo; eso nos anuncia la llegada de Santa Rosa. Dicen que es el camino de Santa Rosa, bien iluminado es ese camino, por allí caminan San Juan y San Pedro [fiestas patronales de otras comunidades] también. Antes de Santa Rosa ya pues es San Juan, eso es después del Corpus. Esta fiesta también es pues su celebración de lo que el sol pasa por el costado, en nuestro pueblo se le ve lo que pasa por Lamas. (Citado en Panduro, 1999, p. 27)

La mayoría de comunidades Lamista celebran su propia fiesta patronal, las cuales se concentran entre junio y septiembre. Durante estos meses, los jóvenes - principalmente los varones- aprovechan para ir de patrona en patrona para buscar pareja. Estos también son los momentos que suelen aprovechar los enamorados para huir juntos y empezar a convivir. Como afirma Simeón Amasifuen Sangama, de la comunidad del Wayku, "los jóvenes en las fiestas también mujean [se intercambian], se empeñan; tiempo de fiesta las mujeres huyen, eso es mujeo también. 'Yo mujeando' dicen, 'ya tanikudo' dicen; la gente mujea en las fiestas, mujo de runa [gente] es eso" (en Choba Choba, 2000, p. 30).

También existen celebraciones para conmemorar los diferentes momentos de la vida. Estas son ocasiones para reunir a la familia y amigos, visitar a los parientes de otras comunidades, bailar y disfrutar de comida y bebida abundante. Una de estas es el lanta tipina o corte de pelo. Otra es la llegada de los jóvenes del servicio militar. Asimismo, cuando una pareja huye para empezar a convivir, el novio, acompañado de su familia extensa, "hace aparecer a la mujer" donde la familia de la novia. Esta ceremonia, que sucede unos días después de la huida, se llama la apresentación (mañacur o warmi ricurichina). El matrimonio se realiza después de un tiempo de convivencia. El corte de pelo y el matrimonio -así como también el corte de luto, realizado seis meses o un año después del fallecimiento de un pariente- son también momentos en los que se puede establecer 
relaciones de compadrazgo con personas no Kichwa. Mediante ello, se fortalecen los vínculos, de característica asimétrica, con socios comerciales, políticos u otras personas de quienes se pueda obtener favores y bienes, pero que también los puede llevar al endeudamiento?

Las comunidades Lamista también celebran sus aniversarios, para el que invitan a los otros poblados y organizan diferentes tipos de campeonatos. Cuando los hijos terminan la escuela primaria y la secundaria, los padres organizan las fiestas de promoción. Así, la vida está impregnada de celebraciones. Ellos se enorgullecen de ser buenos anfitriones. Intentan ofrecer la mejor comida, bebida y música. A pesar de manifestar el esfuerzo que implica asumir la responsabilidad de estas fiestas, la gente disfruta de compartir con sus parientes y amigos que vienen de otras localidades, de competir lúdicamente, de ser generosos y de la alegría de los jóvenes. De esta forma, el deseo de atraer a las personas canaliza la circulación de alimentos, bebidas y música en las fiestas.

La importancia de las fiestas como expresión de la socialidad, se encuentra también en las formas de comunicación con los animales del monte. Estos también tienen sus fiestas, en luna llena. Cuando se reúnen a bailar con el shapingo, su dueño, no se les puede ver. Los sueños con las fiestas de los animales también son una forma de comunicar a los montaraces que se están acercando. Como me contó don Edinson Cachique Sangama, el tío con el que aprendió a ir al monte soñaba que las huanganas bailaban "con música y ropa típica" cuando se le iban a presentar. Luego comentó que la madre o ánima de la huangana (maman huangana, un ave) canta para avisar antes de llegar y, aunque el montaraz no vea a los animales, va a encontrar el camino que ellos hacen. Es también de los animales que los músicos toman las melodías que después entonan para las fiestas. Retomando las reflexiones de Kohn (2013) y Mezzenzana (2018) para el caso de los Ávila Runa y Pastaza Runa, respectivamente, las posibilidades de comunicación no implican que las partes se reconozcan como lo mismo, pero sí como sujetos que comparten formas, en este caso, entonaciones, apariencias y movimientos corporales.

\footnotetext{
La relación con los mestizos de Lamas, históricamente marcada por el endeudamiento con los patrones, es abordada con mayor profundidad por Scazzocchio (1979) y Calderón (2003). Scazzocchio (1979) cuenta cómo estas relaciones permitían a los mestizos acceder a los cultivos y mano de obra de los indígenas de forma gratuita o a menor costo. Por su parte, los Kichwa Lamista aprovechaban estas relaciones para obtener créditos, ayuda en la realización de trámites y protección de otros comerciantes y de las autoridades locales. También los llamaban para solucionar disputas, principalmente entre afines. Cabe mencionar que, hoy en día, existen diferentes mecanismos para resolver estas cuestiones, sea a través de las organizaciones indígenas, de las ONG, de los programas estatales de crédito rural o de bancos privados, entre otros, lo que ha transformado los niveles de asimetría. No obstante, los vínculos de compadrazgo siguen vigentes.
} 


\section{El caminar de los montaraces}

Las mejores épocas para cazar son antes del carnaval, en febrero -también llamada la fiesta del supay o mitan raymi (fiesta del dueño del monte o de la carne de monte)- y para la fiesta de Santa Rosa, en agosto, cuando los árboles del bosque dan abundantes frutos y los animales están gordos.

Los Kichwa Lamista diferencian entre dos tipos de excursiones en el monte. El shishaneo, se realiza en las mismas chacras o en las tierras en barbecho cercanas a sus casas. Se busca a los animales pequeños que se acercan a beber de los manantiales y a comer los granos, los frutos de las palmeras y los otros animales que los humanos crían. De esta manera, la relación con los animales del monte, sin pasar por la domesticación, se centra en el compartir alimentos.

El chapaneo se refiere a las excursiones más largas a lugares donde se pueden encontrar mayor variedad de animales, árboles y otros vegetales que no se encuentran en los bosques cercanos a los pueblos. Estas duran varios días y se realizan en grupo, guiados por alguien que conoce el lugar. En los angostos caminos del monte, también siembran algunos frutales para que coman ellos y los animales. Asimismo, dejan sal en las colpas -donde los animales beben y se bañan- para que se acostumbren a volver a ellas.

El término chapaneo viene del verbo chapay, que el profesor Kichwa Cachique (2007) traduce como mirar, observar, visitar, pasear o registrar. Otro ejemplo de ello es cuando las personas de Alto Pucalpillo se refieren a estas excursiones como "ir a mirar a los animales" (Chaparro, 2018). De la misma forma, en castellano, para expresar que van a visitar a sus parientes, dicen que los van a ir a espiar. Esto lleva a pensar en la importancia de la visión en la constitución de las relaciones. Esta se expresa en varios momentos, como en los viajes por la ingestión de plantas maestras o en los sueños. Mirar también es una acción que se resalta en el procedimiento de imitar, clave en la transmisión de conocimientos.

Los montaraces siguen los caminos de los animales, pero deben tener cuidado de no hacerlo demasiado tiempo porque pueden perderse. En estos casos, se dice que el dueño de los animales, el shapingo, "los hizo perder". Este ser también puede colocar pruebas, enfermar a los montaraces o no soltar a los animales cuando no reconoce a la persona la primera vez que esta va al monte, si no ha preparado su cuerpo. Por este y otros riesgos es necesario ir a la montaña con alguien que la conoce, ya que no todos los caminos son conocidos por todos; salvo los principales 
(como los que llevan a la mina de sal), cada familia posee sus propias purinas -término para referirse a los territorios de caza y recolección que proviene del verbo caminar (puriy) - y estas son respetadas.

Según Scazzocchio, (1979, p. 140) algunas purinas eran consideradas dominios de un yachak (sabio), cuando este lograba amansar las ánimas que vivían allí y alejar, en sus visiones, los espíritus de los otros hombres con quienes competía. Hoy en día, los Lamista también se refieren a los caminos de los montaraces como su dominio o su purina. Esta posesión se constituye a partir de las marcas que se deja en ellos: los tambos que se construyen, los sembríos que se dejan para alimentar a los animales y a las personas en sus recorridos, así como las trampas que se colocan para cazar y que son un riesgo para los extraños. No obstante, esta no se concibe como una propiedad excluyente en el sentido en que implica una relación con las ánimas dueñas del monte, así como un conocimiento que puede ser compartido con otros. En esos casos, lo que se espera de ese otro es que cuide los caminos y lo que se ha dejado en ellos, como en distintas oportunidades han manifestado las autoridades comunales en las negociaciones para llegar a acuerdos sobre sus linderos. Con esto no sugiero la inexistencia de conflictos, sino los criterios que priman en la evaluación de lo que se considera una conducta adecuada y respetuosa.

Esta red de caminos de los Lamista incluye ambos lados de la cuenca del río Mayo y sus afluentes, y distintos sectores de la cuenca del Medio y Bajo Huallaga. Parte de estas montañas, hoy en día, conforman el Área de Conservación Regional Cordillera Escalera, donde fueron denunciados don Ramón y sus parientes, y el Parque Nacional Cordillera Azul, al que los guardaparques les restringen el acceso. Esta actitud, abiertamente contraria a la lógica de cuidado y respeto descrita en el párrafo anterior, lleva a que las personas Kichwa se refieren a ellos como mezquinos (misha), que no saben compartir ni, por lo tanto, mantener buenas relaciones.

Las entidades que administran las áreas de conservación en la región no prohíben por completo la caza, pero la burocracia y las restricciones impuestas (como la prohibición de construir tambos, de tener sembríos de los que se puedan alimentar en sus excursiones y la exigencia de solicitar autorización por escrito antes de ir) tienen un efecto similar. Estos límites no son los mismos cuidados que tienen los montaraces, los cuales los funcionarios no se han preocupado por conocer, por lo menos en el caso de las comunidades no tituladas cuyos pueblos se encuentran en los alrededores de Lamas, que no fueron incluidas en ningún espacio de participación o consulta previa para elaboración y aprobación de las distintas versiones del plan maestro del área. 


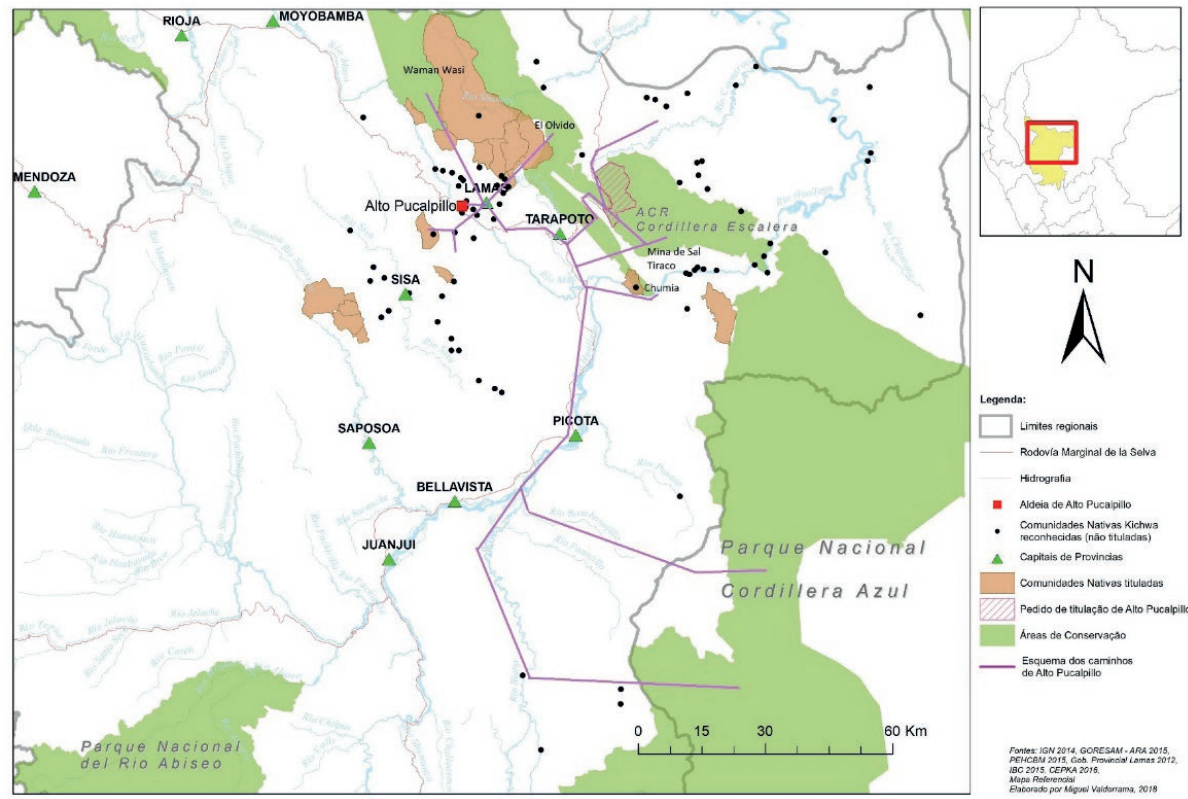

Figura 1. Esquematización de los caminos conocidos por las personas de Alto Pucalpillo. Fuente: Chaparro (2018, p. 118).

\section{Los caminos de la sal}

Unos de los caminos que recorren las familias Kichwa, tanto de Lamas como del Huallaga, son los que llevan hasta la mina de sal de Tiraco. Esta mina, de sal blanca (yurak kachi), está cerca de otros dos domos, de sal roja (puka kachi) y sal morada (sani kachi). Además de esta, existen otras minas de sal conocidas por los Kichwa de San Martin, como las de Pilluana, Kallanayaku y Chipurana. La sal de la montaña fue uno de los principales productos con los que los Kichwa abastecían a las misiones de Mainas y con el que intercambiaban con otros pueblos indígenas en una extensa red de comercio que llegaba al actual Ecuador hasta que se generalizó el consumo de sal industrial (Barclay, 2001 y Valderrama, 2019).

La mina de Tiraco tiene un ánima madre, la Achkin Vieja (achkiy significa estornudar). De acuerdo a don Angel Sangama Amasifuen y su hijo Walter, de Alto Pucalpillo, la Achkin Vieja vivía antes en Tabalosos -otro de los lugares donde se concentró la población indígena desde la época colonial- donde también había una mina de sal. Pero la gente la rechazaba porque, al estornudar, salaba la comida con sus mocos. Un día, ella se enfadó y decidió partir lejos, hasta donde está actualmente, en Tiraco. Según don Walter: 
Duro le han pegado. Y así cuando le han pegado, llorando llorando les ha dicho "nunca más me volverán a ver; no van a agarrar sal cerca; si quieren sal van a ir lejos caminando". Por eso se ha ido de Tabalosos, porque le han asqueado [...]. Pero dice iba cayendo su polvo de la sal. Había a la vez un camino. Alguien le habrá perseguido, algún viejo. Y por mediante de ese polvo de esa sal, han llegado. (Walter, Comunicación personal, agosto de 2017)

Por su parte, en una conversación con doña Virginia Sangama Guerra, esta agregó que después de ser expulsada de Tabalosos, la Achkin Vieja fue primero a Lamas, donde también había una mina de sal. Pero donde también "le asquearon" y partió hacia Tiraco. El polvo que deja esta abuela recuerda al que dejan las personas en el trayecto de su vida y que, al fallecer, recogen al caminar como difuntos los lugares que han conocido.

Como afirma Calavia para el caso de los Yaminawa, los mitos revelan "tramas itinerantes, en las que las relaciones sociales son en esencia las relaciones espaciales. La acción es siempre desencadenada por una partida o una llegada; los héroes matan, mueren o se transforman pero sobre todo andan" (2004, pp. 124-125) y, en ese camino, ganan conocimientos y bienes que definen a las personas. En este caso, este camino está relacionado al conocimiento de la sal.

La sal contribuye a la constitución de un cuerpo fuerte y sano. Según me indicaron en Alto Pucalpillo, bañarse en la quebrada Kachiyaku (agua salada), que nace en Tiraco es bueno para no tener apostemas y curar la picazón, así como para sacar la saladera (mala suerte) y el cansancio del cuerpo. La mala suerte afecta la capacidad de cazar y criar alimentos. Esta puede ser consecuencia de no respetar las restricciones que los hombres y las mujeres deben cumplir, por ejemplo, durante el embarazo o después de la muerte de un pariente. Para combatirla, es necesario ingerir purgas (vegetales con poderes curativos, espíritus fuertes) y cumplir la dieta correspondiente.

A pesar de los intentos por erradicar el consumo de sal de la montaña - principalmente desde las medidas sanitarias contra el cretinismo y bocio en los años sesenta, que impusieron el consumo de sal yodada y durante las cuales entraban a las casas a confiscar, incinerar o botar bactericida a los mazos de sal-, esta sigue siendo la preferida como condimento y es considerada más efectiva para la conservación de los alimentos. Como afirma don Miguel Sangama Cachique, la sal industrializada "no entra en la carne, su encimita nomás y hace podrir la 
carne. ¿Pero a ver con la sal de Tiraque?" (citado en Rengifo, 2009, p. 30). Aunque faltaría hacer un análisis más detallado sobre las distintas dietas, quiero llamar la atención sobre la abstinencia de sal en muchas de ellas. Incluso cuando una dieta no implica abstenerse por completo de comer sal, se recomienda disminuir al mínimo la cantidad. Ello vuelve el cuerpo más frío, lo que permite entrar en un estado de alteridad. Luego, para volver a la socialidad de la vida entre humanos, la dieta se corta empezando poco a poco a comer sal ${ }^{8}$.

\section{Los caminos del agua}

Caminar cargando tinajas llenas de agua es un saber que las mujeres Lamista demuestran en las competencias que a veces organizan en los aniversarios de las comunidades. Cuando visité Alto Pucalpillo, por la fiesta de San Juan, en junio de 2017, algunas de las jóvenes más habilidosas jugaban desafiándose sobre quién llegaba más rápido cargando las tinajas sin usar las manos.

Los pozos u ojos de agua (pukyu) son lugares con mucha vida. Son sembrados y cuidados. Proporcionan el agua para beber a humanos y animales, hacer chicha, cocinar, lavar la ropa y bañarse. También son lugares de encuentro para las mujeres y hábitat de ánimas fuertes.

Los pozos también son nodos que unen los caminos subterráneos del agua. Estos son compartidos por las familias que viven cerca. Para sembrarlos, según dicen, el agua tiene que ser robada de otro lugar, que luego se seca, a la medianoche. Así, también se debe tener cuidado ya que personas de otras comunidades la pueden robar. Según don Ramón Amasifuen Guerra, para robar el agua, esta se lleva en un huingo (Crescentia cujete). Para ello, se le hace un pequeño agujero en el medio del fruto, cuando está verde, para que el agua pueda gotear durante el camino hasta donde va a ser sembrada. Algunos dicen que la persona tiene que ir sola, otros afirman que tiene que ser una niña y otros que tienen que ser un hombre y una mujer desnudos en la noche, cuando nadie los ve. Durante el camino, tienen que ir llamándola, "agüita, agüita, agüita, agüita, por acá, por acá, se dice", me indicó don Ramón. Luego de sembrada, va a filtrar poco a poco. Después de alrededor de dos meses, la tierra empieza a humedecerse y es en ese momento que se tiene que cavar el pozo. En una conversación sobre su cuidado, don Juan Pablo Cachique también me comentó que las mujeres les convidan la leche de su primer hijo para que no se seque, que no se vaya

8 La relación entre el consumo y abstinencia de sal, la transformación corporal y el movimiento entre la socialidad humana y los estados de alteridad se desarrollan con más detalle en Chaparro (2020). 
y aumente el agua. Así, igual que con los animales del monte, la relación de crianza también pasa por el compartir alimentos y asemejar los cuerpos ${ }^{9}$.

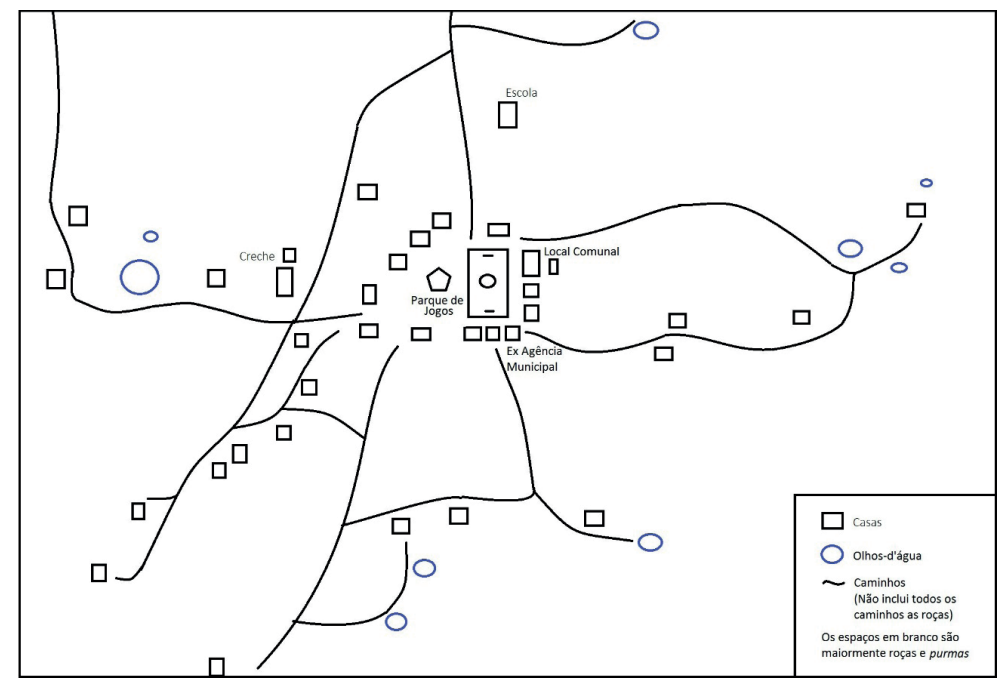

Figura 2. Croquis de los caminos entre las casas y ojos de agua de Alto Pucalpillo. Fuente: Chaparro (2018, p. 105).

\section{Entre las chacras}

El modo de residencia de las familias Lamista suele ser patrilocal. Las tierras se heredan principalmente a los hijos hombres, siendo el menor o el que se queda criando a los padres cuando estos son mayores el que hereda la casa y los terrenos cercanos a esta. A veces, las parejas deciden adquirir tierras en otro lugar con más monte y animales. En algunos casos, esto ha conllevado a que se muden fuera del pueblo, convenciendo a los demás parientes para que los acompañen. En otros, esto solo ha implicado que agreguen un lugar adicional a su residencia multi-localizada. Asimismo, las familias poseen chacras en distintos lugares con el fin de aprovechar la variedad de microclimas y tipos de tierras que existen en la región, favorables para diferentes cultivos (como la tierra negra o yana allpa, tierra roja o puka allpa, tierra amarilla o killu allpa y tierra arcillosa o metu allpa). Esto puede realizarse a través de la apertura de nuevas chacras en un monte alto, mediante la compra de tierras o por medio de la invitación de un familiar para trabajar en su parcela, principalmente en el caso de parejas jóvenes que no tienen cómo acceder a un terreno por su cuenta. Dependiendo de la distancia y accesibilidad - en tanto los caminos varían entre pistas

Para una reflexión más detallada sobre las relaciones de crianza entre distintos seres y su relación con el entorno, ver Chaparro (2018 y 2020). 
afirmadas, trochas carrozables y senderos que solo se pueden recorrer a pie- pueden ir y volver el mismo día o permanecer varias semanas según se requiera realizar actividades de siembra, limpieza o cosecha.

Los alimentos cosechados son compartidos con los habitantes de la casa, con la familia que llega de visita y con la que van a visitar ${ }^{10}$. Este mujeo o intercambio entre parientes, no necesariamente de retribución inmediata, es importante para mantener la diversidad de la chacra. Son las mujeres las que seleccionan, guardan e intercambian las semillas. También son las relaciones de las mujeres con sus padres que viven en otros pueblos las que motivan las visitas (ver también Faiffer y Belaúnde, 2016).

A estas formas de movilidad, se agregan las que realizan los hombres y mujeres Kichwa para trabajar como peones agrícolas en otros pueblos. Los hombres también se emplean en obras de construcción, en fábricas de procesamiento de alimentos, como conductores de motocar (motos de tres ruedas con cabina posterior para llevar pasajeros, principal medio de movilidad cuando no se recorren los caminos a pie) y como músicos en las diferentes fiestas de la región. Por su parte, varias mujeres jóvenes solteras van a trabajar como empleadas domésticas en las ciudades de Lamas, Tarapoto y Lima. Algunas prefieren quedarse, otras no se acostumbran y regresan. También son las mujeres las que salen al mercado de Lamas y Tarapoto o recorren las ciudades, de casa en casa, visitando a sus comadres y conocidas, para ofrecer sus cosechas. A esta relación laboral o de comercio con las ciudades, se suman las visitas que realizan los líderes comunales para gestionar trámites y participar en reuniones con otros funcionarios y autoridades. Los meandros de este camino político se delinean a continuación.

\section{Los caminos de las comunidades nativas}

Según la entidad que administra el área de conservación Cordillera Escalera, no es posible titular las comunidades cuyos principales lugares de residencia se encuentran alejados debido a que, para estos funcionarios, ellas no ocupan ese lugar ${ }^{11}$. Este es el caso de las comunidades de los alrededores de Lamas. Esta interpretación de la noción de ocupación difiere de la que define el Convenio n. ${ }^{\circ} 169$ de la Organización Internacional

10 Sobre la importancia de las visitas en la constitución de las relaciones entre las personas y de estas con los seres de su entorno en una reflexión sobre el movimiento en los modos de socialidad indígena amazónica, ver Mc Callum (2015), a partir de su trabajo con los Huni Kuin.

11 Después de la presión de las organizaciones indígenas, el Gobierno Regional aceptó titular dentro de esta área a las comunidades cuyos principales lugares de residencia se encuentran inmediatamente adyacentes, aunque la promulgación de una nueva norma a finales del 2019, ha suspendido este proceso. Pero, hasta inicios de 2020, no ha habido ninguna disposición a reconocer los derechos territoriales de las comunidades cuyos núcleos poblacionales se encuentran más alejados. 
del Trabajo ${ }^{12}$ y desconoce la residencia multi-localizada y las formas de movilidad de los Kichwa Lamista.

Esta situación nos remite a una de las varias críticas a la forma en que se reconocen los derechos territoriales de los pueblos indígenas de la Amazonía peruana a través de la figura de comunidades nativas, así como a la interpretación que hacen de la legislación y jurisprudencia nacional e internacional los funcionarios del Gobierno Regional de San Martín. Esta categoría jurídica -a partir de la cual demarcan polígonos que engloban un lugar de residencia, las áreas agrícolas y los bosques circundantes - ha generado la división de los lugares compartidos entre familias de diferentes comunidades e interrumpido las redes de caminos que las comunican.

En este contexto, una de las consecuencias de las políticas de conservación no anticipadas por el Gobierno Regional de San Martín, así como de las consecutivas prohibiciones y denuncias contra la población indígena, fue la organización activa entorno a su identidad étnica. Ante las herramientas disponibles para defender sus territorios, aumentaron significativamente las demandas de reconocimiento oficial y de titulación $\operatorname{comunal}^{13}$. La posibilidad de ver interrumpidos sus caminos ha sido una de las principales motivaciones para ser reconocidos oficialmente por el Estado. Así, el número de comunidades Kichwa reconocidas, en San Martín, se incrementó de 18 a 91 entre el 2006 y el 2019.

Hasta el 2015, solo 14 de las comunidades Kichwa oficialmente reconocidas estaban tituladas. Estas fueron tituladas en los años noventa mediante programas de regularización de la propiedad rural implementados como parte de las políticas para incentivar la inversión privada después de la recesión económica y el conflicto armado interno que marcó la década del ochenta. Como afirma García-Hierro (2004), este proceso, al mismo tiempo que posibilitó proteger parte de los territorios habitados por los pueblos indígenas, también permitió que las tierras que quedaron fuera de las delimitaciones comunales sean consideradas dominio del Estado, interesado en promover la inversión minera, petrolera y la agroindustria, en el caso de San Martín, centrada en la producción de palma aceitera.

2 Esta convención, en el Perú, tiene rango constitucional desde 1995 y, en su artículo 13.2, utiliza el término tierras o territorios como la totalidad del hábitat que los pueblos indígenas ocupan o utilizan de alguna u otra manera.

13 El reconocimiento de una comunidad por parte del Estado mediante una resolución es un paso previo para que están puedan solicitar la titulación de tierras comunales. Dentro de este título, de acuerdo a los resultados de un estudio de suelos hecho con esta finalidad, las tierras de aptitud mayor agrícola son dadas en propiedad y las de aptitud mayor forestal y de conservación son otorgadas mediante un título habilitante de cesión en uso. 
En la Amazonía peruana, un hito que ha marcado la lucha del movimiento indígena ha sido el conflicto que tuvo lugar entre el 2008 y 2009, que terminó con un trágico enfrentamiento entre población Awajún y Wampis y la policía nacional, en la región norte de Amazonas, en el que fallecieron 33 personas, conocido como el Baguazo. Esta movilización inició debido a la promulgación de un paquete normativo que flexibilizaba la legislación sobre el uso y gestión de los recursos naturales en los territorios de las comunidades nativas ${ }^{14}$. En San Martín, la población indígena también se movilizó tomando la carretera Fernando Balaúnde Terry. En este caso, el Gobierno Regional firmó una serie de acuerdos suscritos en el Acta de Cacatachi, con el fin de salvaguardar los derechos territoriales de las comunidades, pero no se tradujeron en resultados concretos.

Ante las resistencias del Gobierno Regional frente a la titulación comunal, las organizaciones indígenas de San Martín convocaron nuevamente a una movilización en junio de 2015. Luego de esta, se conformó la Mesa para el Desarrollo de las Comunidades Nativas. Esta mesa se ocupó de revisar la planificación presupuestal y de los conflictos de superposición con otras modalidades de conservación y con los títulos individuales otorgados dentro de los territorios comunales. La presión ejercida motivó al Gobierno Regional a dar los primeros pasos para la titulación colectiva e iniciar el proceso de ocho comunidades con su propio presupuesto.

Este momento coincidió con la incidencia que estaban realizando las organizaciones indígenas a nivel nacional e internacional para reformular el discurso de la conservación a fin de defender sus derechos. Esta logró colocar la obligación de los Estados de garantizar la seguridad jurídica de los territorios indígenas como un tema a ser abordado en la Conferencia de las Partes (órgano supremo de la Convención Marco de las Naciones Unidas sobre Cambio Climático) donde se definen los compromisos de los países en materia ambiental. Como resultado de este proceso, en el Perú, las últimas iniciativas para alcanzar las metas de reducción de emisiones de carbono han incluido rubros presupuestales para la titulación de comunidades nativas ${ }^{15}$. No obstante, las comunidades sobre las que se creó el área de conservación Cordillera Escalera no han podido ser tituladas con estos proyectos.

14 Para mayores detalles sobre este hecho, considerando los distintos informes realizados desde sectores del Estado y sociedad civil, y sus repercusiones en la política nacional, ver Cavero (2011).

15 Los proyectos que se han implementado en San Martín son el Mecanismo Dedicado Específico para pueblos indígenas, que proviene del Fondo de Inversión Forestal, financiado por el Banco Mundial; la Declaración Conjunta de Intención, acuerdo voluntario de cooperación firmado entre los Gobiernos de Perú, Noruega y Alemania; y el Proyecto de Catastro, Titulación y Registro de Tierras Rurales en el Perú, Tercera Etapa, financiado con fondos públicos y un préstamo del Banco Interamericano de Desarrollo. 
En este contexto, los Kichwa Lamista han sido llevados a pensar en fronteras territoriales en lugares compartidos por familias de distintas localidades. Para definir la delimitación de los títulos comunales, han tenido que llegar a acuerdos con sus vecinos indígenas y no indígenas y abrir trochas en los linderos de los territorios comunales. Sin estos, los funcionarios no proceden con la tramitación. La apertura de estos senderos implica una nueva forma de caminar en tanto conlleva a la organización de grupos de mayor número y por rutas distintas a las que suelen recorrer los montaraces. Estas pueden atravesar lugares de difícil acceso que antes no hubieran pensado caminar, pero también despiertan su curiosidad y motivan a las nuevas generaciones a conocer el monte.

Así, son las políticas dictadas por el Ministerio de Agricultura y aplicadas por el Gobierno Regional las que están llevando a las comunidades a establecer divisiones entre ellas, transformando territorios sin límites o con límites fluidos en territorios con fronteras fijas definidas en mapas. No obstante, en algunos casos, estas también están estableciendo acuerdos para permitir que se sigan recorriendo los caminos compartidos.

En este caso, quiero resaltar la importancia del caminar para los Kichwa de San Martín. Esta acción canaliza la relación de los montaraces con el monte y la lucha por la recuperación del territorio. El caminar también expresa la voluntad y fuerza de quien no se cansa. Esta habilidad es muy valorada no sólo en los hombres y mujeres chacareros y montaraces, sino también en los líderes que, aun utilizando los nuevos medios de transporte, viajan a las ciudades para participar en reuniones con los funcionarios del Estado, afrontar las burocracias de los trámites, participar en talleres de capacitación y en las asambleas de sus organizaciones.

Al conversar sobre el reconocimiento de la comunidad nativa de Alto Pucalpillo, don Angel Sangama comentó:

Leonardo [profesor Kichwa que vive en El Wayku] ha venido a decir para formar una comunidad nativa y le hemos hecho pues. Y ahora cómo está caminando. Primera vez cuando han elegido al Apu, a mí ya vuelta me han puesto. Yo he sido el que ha recibido su resolución, duro caminando. Así caminando. Después de 3 años nos han entregado la resolución. Un día 7 de julio nos han entregado y por eso hemos hecho su aniversario el 8 de julio. Ya 10 años. Íbamos en Tarapoto a preguntar si ya está, en el Ministerio de Agricultura. Demoraba. Y esa vez nosotros harto caminábamos. De Naranjal, de Solo, Konkonpera, Mishkiyaku, Nangao, Shukshuyaku [nombres 
otras comunidades]. Así unidos íbamos a reclamar nuestros derechos para que nos entreguen nuestra resolución. (Comunicación personal, agosto 2017)

En una asamblea de Alto Pucalpillo en la que pude participar para discutir las acciones legales que querían emprender debido a su exclusión de los proyectos de titulación, don Walter Sangama Guerra compartió las palabras que reproduzco a continuación. Estas muestran cómo el caminar expresa la relación entre su lucha política por el territorio, la fuerza que se canaliza a través del tejido entre generaciones y distintas comunidades, y la transmisión del conocimiento a través de la experiencia compartida que actualiza la memoria:

No estamos pidiendo un favor, estamos pidiendo un derecho que han dejado nuestros ancestros. Y hay huellas. Y esas huellas nunca se pierden porque esos caminos nunca se pierden. Testigo es el abuelo Custodio que no me va a dejar mentir, que tiene ese conocimiento. Y algunos abuelos que han vivido y lo viven. Ellos también saben. De repente los jóvenes todavía no conocemos. En algunos momentos de repente conocemos pocos. De repente muchos nos engañan cuando no se conoce. Cuando tú conoces, cuando tú le vives, te vas, miras... A veces cuando tú te vas por primera vez a ese tipo de montaña, andas perdido. No sabes ni en dónde estás. Yo de eso les agradezco a nuestros hermanos Apus [autoridades comunales] que han iniciado, que han abierto ese camino [para el reconocimiento y titulación como comunidad nativa]. De repente, no desmayarnos. A seguir trabajando. Invitar también a las comunidades de Morillo, Pukallpa a unirnos. De repente van a pasar años para lograr. No estamos luchando por el interés personal. Estamos luchando para nuestros wambrillos [hijos], para nuestros llullitos [bebés] que están viniendo en camino. De repente nosotros cuando ya estemos ancianitos nos van a recordar nuestros winchos [hijo menor], nuestros nietos, nuestros hijos. Eso más bien yo quería darles ese mensaje de cómo hemos empezado a reconocernos. (Comunicación personal, julio de 2017)

De forma similar, en esa misma oportunidad, don Purificación Cachique Tuanama, abuelo de Alto Pucalpillo, también expresó la relación entre la fuerza que se requiere para alcanzar sus objetivos y la transmisión del conocimiento a través del caminar:

Ahora, el territorio que tenemos por Carachamera, por la mina [de sal], gente que no conoce nos quiere quitar. Nosotros conocemos antes por una trochita yendo. Pero gente ingeniero saben del 
auto satelital [refiriéndose a la forma de conocer el bosque por las imágenes satelitales]. Pero nosotros, como dice don Custodio, nos hemos desmayado. Ahora ya hay jóvenes para que puedan caminar. Nosotros ya estamos un poco de lado. No hay que desmayarnos hermanos, jóvenes, hay que caminar junto con las autoridades, no hay que desmayar. (Comunicación personal, julio de 2017)

Estas palabras resaltan cómo, al igual que los montaraces, los líderes no caminan solos. Bajo la forma de organización de las comunidades nativas, es muy común que el presidente viaje con otras autoridades comunales. Además, necesita el apoyo de su familia, de la comunidad, de las otras comunidades y de los posibles aliados que ayudan a negociar según el lenguaje del Estado y dentro de la economía de la ciudad. Esto implica tanto el soporte emocional para aguantar la nostalgia del tiempo lejos de casa, dejando a la familia sola y sin provisión de alimentos; y la fuerza para caminar más, como cuando las comunidades se organizan para hacer las trochas que demarcan el territorio colectivo. Este soporte da fuerzas para continuar en un contexto con otros peligros y menos generosidad que el monte.

\section{Reflexiones finales}

Los datos aquí presentados llevan a pensar cómo la relación entre los Kichwa Lamista y los lugares que habitan está modelada por poderes que restringen sus movimientos y potencias que los impulsan en diferentes direcciones, incluidas las que los traen de vuelta. A lo largo del tiempo, han debido afrontar las limitaciones de las reducciones de la época colonial, del trabajo forzado que continuó después de la Independencia, el desplazamiento debido al aumento de la inmigración, los riesgos de caminar por las montañas durante el conflicto armado interno y el acaparamiento del territorio en pocas manos, tanto con fines agroindustriales como para la conservación. En este último caso, el enfoque desde el que se ha puesto en práctica la gestión ambiental en San Martín parece preferir que los Lamista se olviden de sus caminos.

Asimismo, en este artículo argumento que el caminar nutre los vínculos que hacen posible la regeneración de la vida al poner en circulación alimentos, afectos, conocimientos y otros bienes. Este movimiento moldea los cuerpos para que sean fuertes y sanos, la personalidad y las relaciones Kichwa Lamista. A partir de ello, muestro cómo el caminar canaliza formas de socialidad que pasan tanto por la crianza de cuerpos semejantes - humanos y no humanos- como por la generación de alianzas con otros (como con los dueños de los animales, los socios 
comerciales, los patrones o los aliados políticos, a quienes a veces se trata de familiarizar) y la apropiación de bienes y saberes ajenos.

Estos caminos pueden entenderse como los hilos del tejido de relaciones múltiples y cambiantes que constituyen el territorio rizomático habitado por los Kichwa Lamista. En este trabajo, he mencionado los caminos a las casas de los parientes, a otras comunidades, a las chacras, a los ojos de agua (lugares de encuentro entre los caminos subterráneos de las aguas y los caminos de la gente), a Lamas, de las personas que salen a trabajar, de los líderes, de los montaraces (que siguen los caminos de los animales), de la sal, de los santos y de las fiestas. Estos últimos son también los caminos de los jóvenes, de los músicos y están vinculados a los caminos de los astros. A su vez, estos se interconectan con los de otras personas, como los investigadores, funcionarios de organizaciones no gubernamentales, del Estado, de los guardaparques de las áreas de conservación, los migrantes andinos y otros que no he podido seguir en esta oportunidad.

Con eso no quiero afirmar una continuidad de los mismos caminos, sino que la memoria se reactualiza volviendo a ellos. Por otro lado, siguiendo las reflexiones de Virtanen (2016), reconocer que los vínculos no están dados ni son estables implica identificar la importancia que tiene el volver para seguir alimentando las relaciones. Así como la memoria de los caminos, la de los cuidados recibidos es reactualizada periódicamente en las visitas a las personas y lugares. Si no son cuidados, existe el riesgo de que estos vínculos se olviden o debiliten. En este sentido, los lugares pueden ser entendidos cómo nodos de atracción insertos es distintas dinámicas de circulación. Entre ellos, algunos son más fuertes que otros. Así, Lamas posee una potencia particular en tanto lugar que concentra a los Kichwa Lamista.

Finalmente, quiero recalcar el valor que los Lamista otorgan a la fuerza y los conocimientos que el caminar necesita y regenera. Es al caminar juntos - con los antiguos, cuyas huellas nunca se pierden, con los jóvenes que están aprendiendo a caminar, cuando se abren las trochas de los linderos comunales, con los líderes, con las otras comunidades, los aliados y para las nuevas generaciones- que se forja en la práctica la noción del territorio como un derecho. Esta es una forma relativamente reciente de concebir la relación entre las personas, los lugares que habitan y los caminos que recorren. No obstante, al mismo tiempo que esta ha cobrado fuerza en la nueva red de alianzas y hostilidades con la que se vinculan los Kichwa de San Martín, hoy en día, este modo de conocimiento también se incorpora como un camino más a seguir, sin desmayarse, para dar continuidad a las relaciones de crianza. 


\section{Referencias bibliográficas}

Albert, B. y Le Tourneau, F. (2007). Ethnogeography and Resource Use among the Yanomami: Toward a Model of "Reticular Space". Current Anthropology, 48(4), 584-592. DOI: 10.1086/519914

Barclay, F. (2001). Cambios y continuidades en el pacto colonial en la Amazonía. El caso de los indios Chasutas del Huallaga Medio a finales del siglo XIX. Bulletin de l'Institut français d'études andines, 2(30), 187-210. DOI: 10.4000/bifea.6994

Belaúnde, L.E. (2001). Viviendo bien: género y fertilidad entre los Airo-Pai de la Amazonía peruana. Lima: Centro Amazónico de Antropología y Aplicación Práctica.

Bonilla, O. (2006). O bom patrão e o inimigo voraz: predação e comércio na cosmologia Paumari. Mana: Estudos de Antropologia Social, 11(1), 41-66. DOI: 10.1590/S010493132005000100002

Cachique, S.F. (2007). Diccionario Kichwa-Castellano / Castellano-Kichwa. Tarapoto: Aquinos Calavia, O. (2004). Mapas Carnales. El territorio y la sociedad Yaminawa. En A. Surrallés y P. García-Hierro (orgs.), Tierra adentro: Territorio indígena y percepción de entorno (pp. 121-135). Copenhague: IWGIA.

Calderón, L. (2003). Relaciones interétnicas entre mestizos e indígenas Kechwa en Lamas en el contexto de la globalización. En C.I. Degregori (org.), Comunidades locales y transnacionales: Cinco estudios de caso en el Perú (pp. 13-104). Lima: Instituto de Estudios Peruanos.

Cavero, O. (2011). Después del Baguazo: informes, diálogo y debates. Cuaderno de trabajo n. ${ }^{\circ} 13$. Serie Justicia y Conflictos No1. Lima: Departamento de Ciencias Sociales. Pontificia Universidad Católica del Perú.

Chaparro, A. (2018). Caminhos de criação Kichwa Lamista: relações entre pessoas e lugares de Alto Pucalpillo (tesis de maestría). Universidade Federal Fluminense, Niterói, Brasil.

Chaparro, A. (2020). Entrelazamientos entre cuerpos y territorio en la crianza Kichwa Lamista. Amazonía peruana, 16(33), 87-108.

Chaparro, A. y Valderrama, M. (2017). Políticas de conservação e direitos territoriais dos povos indígenas: O caso da região San Martín, Perú. Habitus, 15(1), 73-92. DOI: 10.18224/hab. v15i1.5901

Choba Choba. (2000). Compartiendo las crianzas. Lima, Perú: Asociación Rural Amazónica Andina Choba Choba.

Da Matta, R. (1976). Um mundo dividido: a estrutura social dos índios apinayé. Rio de Janeiro: Editora Vozes.

Deluze, G. y Guattari, F. (2012 [1980]). Mil mesetas. Capitalismo y esquizofrenia. Valencia: Pre-Textos.

Faiffer, G. y Belaúnde, L.E. (2016). Mujer, biodiversidad y seguridad alimentaria en las comunidades Kechua-lamas. Lima: Waman Wasi, PRATEC.

García-Hierro, P. (2004). Territorios indígenas: tocando a las puertas del Derecho. En A. Surrallés y P. García-Hierro (orgs.), Tierra adentro: territorio indígena y percepción del entorno (pp. 277-306). Copenhague: IWGIA. 
Gow, P. (1989). The perverse child: desire in a native Amazonian subsistence economy. Man, 24(4), 567-582.

Gow, P. (1991). Of Mixed Blood: Kinship and History in Peruvian Amazonia. Oxford: Clarendon Press.

Gupta, A. y Ferguson, J. (1997). Discipline and Practice: "The Field" as Site, Method, and Location in Anthropology. En A. Gupta, y J. Ferguson (eds.), Anthropological Locations: Boundaries and Grounds of a Field Science (pp. 1-46). Berkley: University of California Press.

Ingold, T. (2002). The Perception of the Environment: Essays on Livelihood, Dwelling and Skill. New York: Taylor \& Francis e-Library.

Ingold, T. (2009). Against space: place, movement, knowledge. En P. Kirby (org.), Boundless Worlds: An Anthropological Approach to Movement (pp. 29-43). New York: Berghahn Books.

Ingold, T. (2011). Being Alive: Essays on Movement, Knowledge and Description. Abingdon: Routledge.

Ingold, T. y Lee, J. (2008). Ways of Walking: Ethnography and Practice on Foot. Burlington: Ashgate Publishing.

Kensinger, K.M. (1995). How real people ought to live: the Cashinahua of eastern Peru. Prospects Heights: Waveland Press.

Kohn, E. (2013). How Forests Think: Toward an Anthropology Beyond the Human. Berkeley y Los Angeles: University of California Press.

Lima, T. (2002). O que é um corpo? Religião e Sociedade, 22(1), 9-20.

Mc Callum, C. (1996). The Body That Knows: From Cashinahua Epistemology to a Medical Anthropology of Lowland South America. Medical Anthropology Quarterly, 10(3), 347-372. DOI: 10.1525/maq.1996.10.3.02a00030

Mc Callum, C. (2015). Espaço, pessoa e movimento na socialidade ameríndia: sobre os modos Huni Kuin de relacionalidade. Revista de Antropologia, 58(1), 223-256. DOI: 10.11606/2179-0892.ra.2015.102107

Mezzenzana, F. (2015). Living through forms: similarity, knowledge and gender among the Pastaza Runa (Ecuadorian Amazon) (tesis doctoral). The London School of Economics and Political Science, Londres, Inglaterra.

Mezzenzana, F. (2018). Moving alike. Movement and human-nonhuman relationships among the Runa (Ecuadorian Amazon). Social Anthropology, 1-15. DOI: 10.1111/14698676.12486

Overing, J. (1977). Orientation for paper topics e Comments. Simposio Social Time and Social Space in Lowland South American Societies, XLII. En Actes du XLII Congrès International des Américanistes vol.2 (pp. 9-10 y pp. 387-394). Paris: Societé des Américanistes.

Panduro, R. (1999). Agricultura campesina Alto Amazónica y Biodiversidad. En M. Arévalo, R. Panduro, A. Quinteros y G. Rengifo (eds.), Hacer brillar la chacra. Agricultura campesina Alto amazónica. San Martín (pp. 11-68). Lima: PRATEC. 
Panduro, R. (2012). La Juventud en la vivencia de los Kechwas Lamas de la región San Martín. En G. Rengifo y G. Faiffer (eds.), Concepciones de juventud en la visión andino amazónica (pp. 291-300). Lima: PRATEC.

Panduro, R. y Rengifo, G. (2001). Montes y montaraces: la visión del bosque en los QuechuaLamas. Una aproximación. Lima: PRATEC.

Rengifo, G. (2009). Los caminos de la sal: el regreso al territorio excluido. Efectos del Fondo de Iniciativas de Afirmación Cultural (FIAC) en la recuperación de los ámbitos de comunidad de los Quechua-lamas. Lima: PRATEC.

Scazzocchio, F. (1978). Curare kills, cures and binds: change and persistence of Indian trade in response to the contact situation in the North-western Montaña. Cambridge Anthropology, 4(3), 30-57.

Scazzocchio, F. (1979). Etnicity and Boundary maintenance among peruvian forest Quechua (tesis doctoral). University of Cambridge, Cambridge, Inglaterra.

Seeger, A., Da Matta, R. y Viveiros De Castro, E. (1979). A construção da pessoa nas sociedades indígenas brasileiras. Boletim do Museu Nacional, 32, 2-19.

Tapullima, L. (2012). Waynakuna-shipashkuna en la vivencia Kechwa Lamas. San Martín. Perú. En G. Rengifo y G. Faiffer (eds.), Concepciones de juventud en la visión andino amazónica (pp. 301-340). Lima: PRATEC.

Valderrama, M. (2019). O sal da montanha. Notas etnográficas sobre relações de domínio e a circulação do sal numa aldeia do Bajo Huallaga na Amazônia peruana (tesis de maestria). Universidade Federal Fluminense, Niterói, Brasil.

Vilaça, A. (1992). Comendo como gente: formas do canibalismo Wari. Rio de Janeiro: UFRJ/ ANPOCS.

Virtanen, P.K. (2016). Relational Centers in the Amazonian Landscape of Movement. En N.G. Bon y J. Repič (orgs.), Moving Places. Relations, Return and Belonging (pp. 126-147). New York: Berghahn Books.

Viveiros De Castro, E. (1979). A fabricação do corpo na sociedade xinguana. Boletim do Museu Nacional, 32, 40-49.

Viveiros De Castro, E. (1998). Cosmological deixis and Amerindian perspectivism. Journal of the Royal Anthropological Institute, 4, 469-88. 